\title{
A BATALHA DA COPEL: GOVERNO, PARLAMENTO E MOVIMENTO SOCIAL EM AÇÃO, de Cátia Cilene Farago ${ }^{1}$
}

\author{
Leonardo David Micheleto ${ }^{2}$
}

- Enviado em 20/02/2016

- Aprovado em 24/02/2016

Cátia Cilene Farago é formada em Filosofia pela Universidade Federal do Paraná e em Direito pelo Centro Universitário Curitiba. É mestre em Sociologia também pela UFPR, resultando daí a obra da resenha em questão. Atualmente é doutoranda em Sociologia pela UFPR, com o mesmo orientador Ricardo Costa de Oliveira, em que vem pesquisando a trajetória de José Richa e as eleições de 1982.

A dissertação em questão aborda um marco histórico na política paranaense, que ficou conhecida como “A Batalha da Copel”. Vários pontos são abordados, desde uma análise sobre o neoliberalismo desde seu berço (o liberalismo), passando pelo jogo político por dentro do parlamento paranaense até o Fórum Popular Contra a Venda da Copel, tudo isso girando em torno da polêmica sobre a privatização da Copel, sendo conduzida pelo segundo mandato do então governador Jaime Lerner.

O primeiro capítulo, intitulado "Do Estado liberal ao Estado neoliberal", traz o Estado desde o seu surgimento como Estado burguês ao lado da ideologia nascente junto a ele, para legitimar a

\footnotetext{
${ }^{1}$ Dissertação de autoria de Cátia Cilene Farago, defendida no Programa de Pós-Graduação em Sociologia da UFPR, na linha Sociedade e Estado, em 2006, sob orientação do Prof. Dr. Ricardo Costa de Oliveira. Versão completa disponível na Biblioteca Digital da UFPR - file:///C:/Users/User/Downloads/FAGARO,\%20CATIA\%20CILENE\%20(1).pdf.

${ }^{2}$ Graduado em História pela Universidade Federal do Paraná. Membro do Núcleo de Estudos Paranaenses (NEP). Endereço eletrônico: leonardo_micheleto@ hotmail.com
} 
ascensão burguesa. O liberalismo nasce no século XVII na França, no contexto de desenvolvimento capitalista, com a propriedade privada e a atividade comercial como caráter central dessa nova classe. Num primeiro momento assume um caráter político-jurídico, em que a igualdade e liberdade eram condições jurídicas, não socioeconômicas. Os princípios do mercado foram transformados em leis. A técnica se transformou em método para a exploração do trabalho dos outros, em busca de dominação e poder. O contrato substitui o status, a ciência substitui a religião. Uma nova filosofia aparece para legitimar as transformações, baseada no progresso e na razão, como um papel preponderante do Iluminismo. Há uma valorização do indivíduo e do cidadão, a liberdade sendo vista como direito natural do homem, o que levou no século XIX à economia de livre-mercado.

O neoliberalismo tem origem no liberalismo clássico, mas não é uma simples continuação, têm origens históricas distintas. O liberalismo clássico tem origem contra o absolutismo divino, enquanto que o neoliberalismo tem origem contra o Estado de Bem-Estar Social, intervencionista e keynesiano. Seus pontos de continuidade principais são: defendem a propriedade privada, a não intervenção do Estado, a idéia de liberdade (para fazer negócios) e o acento sobre o indivíduo (iniciativa).

O neoliberalismo começa a ser pensado no período pós-guerra, no momento de expansão do Estado de Bem-Estar Social intervencionista e keynesiano, nos Estados Unidos e na Europa. Ele prepondera após a crise dos anos 1970, com o desgaste do modelo fordista-keynesiano e com a ascensão da acumulação flexível, nova etapa de reformulação do capital após sua crise, segundo David Harvey. A acumulação flexível vem em confronto direto com a rigidez do fordismo, trazendo flexibilidade dos processos de trabalho, dos produtos e dos padrões de consumo, surgimentos de novos setores, inovações, rápidas mudanças dos padrões de desenvolvimento desigual, além de uma compressão do espaço-tempo e desemprego estrutural. O trabalho organizado é solapado e o capital financeiro é o poder coordenador. O individualismo se encaixa.

As privatizações têm o neoliberalismo como fonte, mas não são medidas isoladas. $\mathrm{O}$ neoliberalismo se apresenta sobre a forma de "reformas", com a justificativa de tornar a sociedade brasileira mais competitiva numa era de globalização econômica. Constitui-se num padrão antigo de política, utilizando aparelhos coercitivos locais e têm suas políticas formuladas pelos organismos internacionais, discursos de cima para baixo e, segundo a autora, "lavagem cerebral" (promessas de melhorias, eficiência e baixos preços). Os mecanismos funcionam da seguinte forma: o governo financia a compra no leilão, vende moedas podres a longo prazo e ainda financia os investimentos que os compradores precisam fazer. E, para aumentar o lucro dos futuros compradores, o governo 
engole dívidas bilionárias, demite funcionários, investe maciçamente e até aumenta tarifas e preços antes das privatizações.

Acontece os escancaramento as importações, a destruição de milhões de empregos, a dívida do Tesouro, a falência de Prefeituras e Estados, o assalto contra aposentados e funcionários públicos, as privatizações de empresas gigantescas, tudo com apoio dos meios de comunicação. Com os impactos de concentração de renda, lucros rápidos das empresas privatizadas com os custos absorvidos pelo Estado, o enfraquecimento da democracia e a perda do controle de funções essenciais de setores da economia, de fontes lucrativas de acumulação, desarticulando a economia.

A classe política oscilou de um conjunto de convicções para um novo conjunto de convicções. As democracias ocidentais pensam no fundo a mesma coisa, ficando de fora dos extremos. Segundo Max Weber, os indivíduos da classe política não apenas vivem para a política, mas da política, e, apesar das variações ideológicas, eles têm interesses em comum, que são os benefícios. A disputa entre parlamentares é feita com vistas a participar do poder ou influenciar a divisão do poder.

Nesse sentido, segundo Raimundo Faoro, o constitucionalismo moderno funciona como um sistema de freios e controles ao poder, garantindo a divisão do poder. A autonomia de ação vem com as esferas separadas de poder. A conquista de uma Constituição significa a extinção do absolutismo e do poder arbitrário, estabelecendo-se o governo da lei, como expressão de um poder independente, o Poder Legislativo. As assembléias legislativas são meios preventivos para limitar e controlar o poder, preparando a sociedade para a mudança política, por meio de uma moldura jurídica, para evitar a ruptura revolucionária. Já as Assembléias Constituintes dão a legitimidade necessária, já que sem a participação do povo, o governo não será um governo constitucional.

A Constituição de 1988 traz um caráter democrático, de governabilidade e representação. Farago traz a discussão sobre o sistema política brasileiro. Segundo Grohmann, se desenvolveu no Brasil um sistema legislativo adequado ao mundo parlamentarista, quando o sistema de poder é presidencialista, gerando possibilidades de situações de engessamento e ingovernabilidade, de poder sem responsabilidade. Para Mainwaring, a combinação do sistema eleitoral proporcional e do sistema multipartidário com o presidencialismo é uma das piores combinações, pois há muitas chances de gerar instabilidade. Para Abrucio e para Figueiredo e Limongi, a Constituição de 1988 fortaleceu o Poder Legislativo. Para o primeiro, somente em âmbito federal, para os segundos foram mantidos muitos dos poderes legislativos com os quais o Poder Executivo foi dotado ao longo do período autoritário. Na predominância do Executivo, o Congresso é mais um facilitador que um 
obstáculo. O sistema político favorece as competições intrapartidárias e o clientelismo. Assim como para Mainwaring, para quem desde 1930 os políticos agem de modo livre e autônomo, sem interesse de fortalecer os partidos, favorecendo o personalismo e o clientelismo.

Dessa forma foi também o caso dos mandatos do governador do Paraná Jaime Lerner (19942002). Lerner teve sua origem como tecnoburocrata vinculado ao engenheiro Ivo Arzua Pereira, do PDC, prefeito de Curitiba em 1962, apoiado por Ney Braga. Este foi governador (1961 - 1966) com ideologia industrialista e desenvolvimentista. Lerner adere ao neyismo, que consiste no predomínio de membros tecnocráticos no governo, alguns com passagens na iniciativa privada e consultores em empresas nacionais e internacionais. Lerner logrou êxito profissional no planejamento urbano, o que o deu projeção midiática. Em 1971 foi prefeito pela ARENA, e, com o fortalecimento político de Ney Braga com o presidente Geisel, foi novamente nomeado prefeito no fim da década, pelo então governador Braga. Com o multipartidarismo da redemocratização houve uma reorganização e Lerner acaba se ligando ao PDT de Lionel Brizola, como estratégia política, pois não tinham proximidade ideológica - Lerner era ligado ao setor conservador da elite paranaense. Em 1994, é eleito governador em primeiro turno, e aparece publicamente apoiando Fernando Henrique Cardoso para o pleito presidencial. Em 1997, Lerner deixa o PDT e migra para o PFL, acompanhado por vários secretários estaduais, municipais, vereadores, prefeitos, vice-prefeitos e tecnoburocratas que o seguiam. Em 1998 foi reeleito, mostrando um entrosamento com FHC e com a elite conservadora descendente da ARENA que o gerara. Já quando teve início seu governo, foi aprovado um projeto de lei que autorizava a Copel a se associar a empresas privadas como acionista minoritária na execução de projetos nas áreas de produção e distribuição de energia elétrica. Nessa época já havia um desgaste de sua imagem, e achava que a venda da Copel poderia reverter esse quadro.

Mas o que Lerner provavelmente não imaginava é que teria uma oposição tão forte, já que em 1998 o projeto de lei de privatização tinha passado com tranqüilidade (33 votos contra 13) e contava com 40 deputados em sua base aliada. Porém, em 2001, quando foi retomado o processo para a efetivação da venda da estatal, foi articulado o Fórum Popular Contra a Venda da Copel, que teve sua primeira reunião em fevereiro de 2000, no Plenarinho da Assembléia Legislativa, com a participação de partidos, movimentos sociais, entidades da sociedade civil, etc. O CREA-PR puxou, ao lado de associações, sindicatos e federações diversas. Fórum se tornou um movimento organizado com uma boa agenda de ações: mutirão de coletas de assinaturas, mobilização para aprovação do PL 13/2001, atos públicos e várias outras atividades mobilizadoras, com grande participação popular. Teve início com mais de quarenta entidades, dentre elas a CUT, o MST, o 
CNL/CNBB, a Força Sindical, o Sinditest, alguns senadores (Alvaro Dias, Arns), a OAB-PR. Em três meses eram mais de quatrocentas entidades, dentre elas até entidades capitalistas, como a Associação Comercial do Paraná e a FIEP, que queriam postergar a venda. O movimento tinha uma ideologia e um caráter antiprivatização, nacionalista e regionalista. O paranismo é expresso em vários materiais divulgados.

A mobilização do Fórum culminou no episódio de votação do Projeto de Iniciativa Popular Contra a Venda da Copel, um marco na história da Alep e do Paraná e um divisor de águas na política. Foi o primeiro projeto de lei de iniciativa popular da história das assembléias estaduais e a sessão mais longa da história da Assembléia Legislativa do Paraná, durando vinte e duas horas e só parando por conta de uma ocupação de manifestantes, dentre eles estudantes, professores, funcionários públicos. Começou no dia 14 de agosto de 2001 e terminou no dia 15 de agosto, sem votação. Dentre o período todo do jogo político que envolveu a venda da Copel, várias manobras foram feitas de ambos os lados, Por exemplo, em 1998, quando da primeira votação, o então presidente da Alep, Aníbal Khury, determinou, depois da vitória na votação, que o plenário fosse transformado em Comissão Geral, dessa forma as emendas da oposição não voltariam para a Comissão de Constituição e Justiça. A oposição, por sua vez, em 2001, fazia o possível para adiar a votação, dessa forma ganhando tempo para ganhar mais apoiadores e fortalecer ainda mais o movimento, com o primeiro signatário do projeto de iniciativa popular se escondendo dentro da Assembléia, pois ele deveria ser a pessoa a apresentar o projeto.

De qualquer forma, a oposição e o Fórum Popular Contra a Venda da Copel fizeram um trabalho político muito eficaz, pois a votação do projeto de iniciativa popular ficou em 27 votos para os governistas contra 26 votos para oposição, mudando completamente o quadro político dentro da Assembléia. Isso que ainda houveram denuncias de irregularidades por parte da oposição, que, após perder o pleito, foi tentar a luta jurídica. Para apresentar tal projeto, eram necessárias assinaturas de $1 \%$ da população eleitoral do estado, o que representava à época 63 mil assinaturas. O Fórum conseguiu mais de 120 mil assinaturas, em diversos municípios. Além disso, a oposição logrou êxito ao ampliar o debate para a sociedade civil, saindo apenas do Poder Legislativo, e ainda soube jogar com os deputados governistas que oscilavam. Esses tinham acordo com governo, para que votassem a favor da privatização em troca de recursos para as suas bases eleitorais, o clientelismo do sistema discutido acima. Porém, tinham receio que o governo esquecesse o acordo, pois o governo dizia que a verba sairia justamente da venda da Copel. 
A votação do projeto de iniciativa popular foi o ápice do movimento, e a entrega simbólica do projeto contou com um ato com 25 mil manifestantes segundo o Fórum, e 3 mil segundo a Polícia Militar. No dia da votação aconteceram vários tumultos, com deputados saindo às vias de fato em plena Assembléia, com repressão policial dentro e fora da Alep, com a presença da Tropa de Choque da PM agredindo inclusive deputados da oposição. Na nova sessão do dia 20 de agosto, houve mais repressão ainda, com deputados federais assintindo.

Apesar da vitória do governo na votação, a privatização acabou não ocorrendo, com a alegação que não havia compradores quando do leilão, e a privatização acabou sendo suspensa pelo Supremo Tribunal de Justiça. E no final do processo, o governo e os deputados governistas saíram extremamente desgastados, de forma que nas eleições seguintes, de 2002, dos 27 deputados da situação, 10 não se reelegeram, e os reeleitos tiveram que se reagrupar de acordo com o "novo" quadro, torno dos partidos, PSDB, PMDB e PDT.

A partir dos anos 1990, os movimentos sociais tiveram posturas mais ativas, formando redes com outros atores sociais, dentro dos marcos da institucionalidade e não mais à margem. Essas novas práticas trazem mais conhecimento sobre a política estatal. O perfil se alterou, agora existem movimentos globais. A globalização hegemônica também traz em contrapartida a globalização contra-hegemônica, que luta contra as injustiças do neoliberalismo. É nessa década que no Brasil entra em voga a teoria da dependência para os movimentos sociais e teóricos políticos, em que os marginais são vistos como produto do modelo capitalista implantado nos países subdesenvolvidos, que tem papel estratégico para a acumulação, oferecendo superexploração e exército reserva de mão-de-obra desqualificada oriunda do campo. Muitas lutas se dão em torno dos sindicatos. Esse é o contexto de surgimento do Fórum Popular Contra a Venda da Copel. 